\title{
Optimalisasi Penempatan Kapasitor Bank untuk Memperbaiki Kualitas Daya Pada Sistem Kelistrikan PT. Semen Indonesia Aceh Menggunakan Metode Genetic Algorithm (GA)
}

\author{
Aulia Bagus Ar Rahmaan, Ontoseno Penangsang, Ni Ketut Aryani \\ Jurusan Teknik Elektro, Fakultas Teknologi Industri, Institut Teknologi Sepuluh Nopember (ITS) \\ Jl. Arief Rahman Hakim, Surabaya 60111 Indonesia \\ e-mail:rbagus38@gmail.com
}

\begin{abstract}
Abstrak-Kualitas daya dalam sistem tenaga merupakan hal yang sangat penting dan harus diperhatikan untuk menjaga stabilitas dan continuitas sistem tenaga listrik dalam suatu industri. Diantara permasalahan kualitas daya yang timbul salah satunya adalah penurunan nilai power factor yang menyebabkan konsumsi daya menjadi berlebih. Seperti pada industri industri besar pada umumnya. Pabrik Semen Indonesia Aceh juga memiliki permasalahan kualitas daya pada sistem kelistrikannya, disebabkan karna mempunyai banyak motor motor berkapasitas besar untuk proses produksinya. Pemasangan kapasitor pada sistem adalah salah satu cara untuk memecahkan permasalahan ini. Fungsi kapasitor adalah untuk pasokan daya reaktif sehingga kapasitor dapat memperbaiki faktor daya dan drop tegangan sehingga dapat memperkecil kerugian daya pada sistem. Didalam sistem kelistrikan PT. Semen Indonesia Aceh memiliki banyak variasi beban bus sehingga memasang kapasitor perlu mempertimbangkan optimalisasi lokasi penempatan dan kapasitas kapasitor. Pada tugas akhir ini akan mempelajari optimalisasi penempatan dan ukuran kapasitor bank pada sistem kelistrikan PT. Semen Indonesia Aceh untuk memperbaiki kualitas daya dengan menggunakan metode Genetic Algorithm dan hasil yang didapat akan dianalisa sebagai hasil dari tugas akhir yang akan dikerjakan.
\end{abstract} $(\boldsymbol{G A})$.

Kata Kunci-Power Factor, Kapasitor Bank, genetic algorithm

\section{PENDAHULUAN}

$\mathrm{P}$ T. Semen Indonesia Aceh merupakan bagian dari perusahaan BUMN Semen Indonesia yang berlokasi di Aceh. Perusahaan ini bergerak dibidang industri pembuatan semen berkapasitas 3 juta ton per tahun, di atas lahan seluas 1.500 hektar yang direncanakan untuk memenuhi kebutuhan semen di wilayah pulau Sumatera bagian utara dan sekitarnya. Seperti pada industri industri besar pada umumnya. pabrik Semen Indonesia Aceh ini memiliki permasalahan kualitas daya pada sistem kelistrikannya, disebabkan karna mempunyai banyak motor motor berkapasitas besar untuk proses produksinya. Diantara permasalahan kualitas daya yang timbul salah satunya adalah penurunan nilai power factor yang menyebabkan konsumsi daya yang menjadi berlebih [1]. Untuk itu diperlukan analisa dan solusi terhadap sistem kelistrikannya guna mengurangi dampak akibat permasalahan kualitas daya tersebut.
Pada tugas akhir ini, Genetic Algorithm merupakan metode yang akan digunakan untuk memecahkan suatu masalah pada jaringan distribusi radial [2]. pencarian nilai dalam masalah optimasi dan juga penentuan lokasipemasangan kapasitorbank yang menjadi fokus pembahasan dan pencarian solusi di tugas akhir ini. Yang bertujuan untuk menempatkan pada jaringan bus yang tepat untuk mendapatkan nilai power faktor yang bagus pada sistem kelistrikan tersebut. Metode ini diterapkan pada jaringan distribusi radial pada sistem kelistrikan real PT Semen Indonesia Aceh. dengan beberapa percobaan kemungkinan yang berbeda. Hasil yang diharapkan nantinya ialah mendapatkan power factor yang bagus dan rugi daya terkecil dengan membandingkan setiap studi kasus yang dilakukan menggunakan software MATLAB dengan hasil simulasi software ETAP 12.6.

\section{SISTEM TENAGA LISTRIK, KUALITAS DAYA, KAPASITOR BANK}

\section{A. Sistem Distribusi}

Sistem tenaga listrik meliputi sistem pembangkitan, sistem transmisi dan sistem distribusi. Sistem distribusi mempunyai peranan yaitu untuk menyalurkan dan mendistribusikan tenaga listrik ke masing-masing beban atau konsumen dengan mengubah tegangan listrik yang didistribusikan menjadi tegangan yang dikehendaki, karena kedudukan sistem distribusi merupakan bagian paling akhir dari keseluruhan sistem tenaga listrik yang mempunyai fungsi mendistribusikan langsung tenaga listrik pada beban atau konsumen yang membutuhkan.

Dalam pendistribusian tenaga listrik ke konsumen, tegangan listrik yang digunakan bervariasi tergantung dari jenis konsumen yang membutuhkan. Untuk konsumen industri biasanya digunakan tegangan menengah $20 \mathrm{KV}$ atau $6,3 \mathrm{KV}$.

\section{B. Sistem Jaringan Distribusi Radial}

Sistem distribusi dengan pola Radial adalah sistem distribusi yang paling sederhana dan ekonomis. Pada sistem ini terdapat beberapa penyulang yang menyuplai beberapa gardu distribusi secara radial. Jaringan distribusi sistem radial ditandai dengan adanya satu jalur pengiriman tenaga listrik mulai dari sumber gardu induk ke pelanggan. Sistem distribusi radial terdiri dari satu atau lebih trafo distribusi dan memiliki cabang-cabang 
menuju beban. Jaringan ini adalah topologi jaringan yang paling banyak digunakan seperti pada gambar 2.1

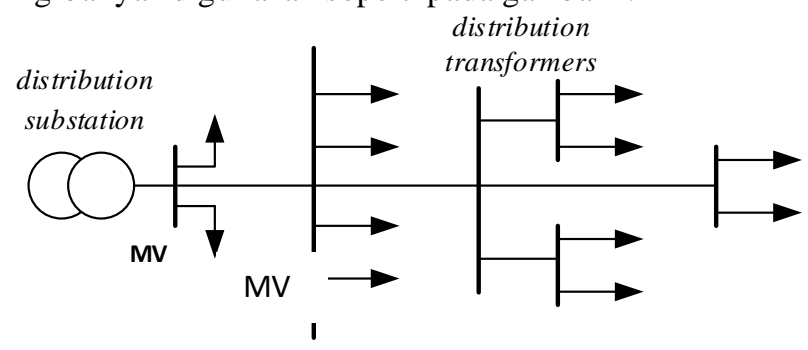

Gambar 1 Sistem Jaringan Distribusi Radial

Catu daya berasal dari satu titik sumber dan karena adanya pencabangan-pencabangan tersebut, maka arus beban yang mengalir disepanjang saluran menjadi tidak sama sehingga luas penampang konduktor pada jaringan bentuk radial ini ukurannya tidak sama karena arus yang paling besar mengalir pada jaringan yang paling dekat dengan gardu induk. Sehingga saluran yang paling dekat dengan gardu induk ini ukuran penampangnya relatif besar dan saluran cabang-cabangnya makin keunjung dengan arus beban yang lebih kecil mempunyai ukuran konduktornya lebih kecil pula.

Kelebihan jaringan sistem radial secara umum adalah bentuknya yang sederhana dan biaya investasi yang relatif murah. Sedangkan kelemahannya adalah kualitas pelayanan dayanya relative jelek yang disebabkan rugi daya dan drop tegangan cendrung besar. Kemudian kontiniunitas penyaluran daya yang kurang handal.

\section{Kualitas Daya}

Masalah kualitas daya didefinisikan sebagai semua masalah yang berhubungan dengan daya listrik yang berupa penyimpangan tegangan, arus dan frekuensi yang mengakibatkan kerusakan pada peralatan peralatan listrik. Berikut macam macam kualitas daya :

- Faktor daya

- Harmonisa

- Perubahan tegangan

- Tegangan transien

- Ketidakseimbangan tegangan dan fasa

- Distorsi bentuk gelombang

- Perubahan frekuensi

- Tegangan kedip

\section{Faktor Daya}

Faktor daya merupakan salah satu indikator baikburuknya kualitas daya listrik. Faktor daya atau factor kerja adalah perbandingan antara daya nyata (watt) dengan daya kompleks (VA). Peningkatan daya reaktif akan meningkatkan sudut antara daya nyata dan daya kompleks, sehingga dengan daya aktif yang tetap akan mengakibatkan peningkatan daya nyata yang akan dikirimkan lebih besar, Dengan kata lain akan menurunkan efisiensi dari sistem distribusi ketenagalistrikan

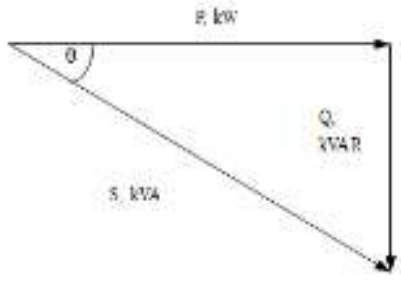

Gambar 2 Diagram Phasor

Faktor daya juga disimbolkan sebagai $\cos \theta$, dimana :

$$
\cos \theta=p f=\frac{p}{s}
$$

Seperti terlihat pada persamaan 1 , nilai faktor daya tertinggi adalah 1. Sistem dengan faktor daya seperti ini memiliki efisiensi yang sangat baik dimana hal ini berarti daya kompleks (VA) yang dibangkitkan digunakan secara utuh pada beban resistif (W). Dalam hal ini nilai daya kompleks (VA) sama dengan daya aktif (W).

Dalam perhitungan daya, faktor daya memegang peranan sangat penting. Faktor daya merupakan ukuran daya yang dikirim antara sumber dan beban. Faktor daya bervariasi antara 0 sampai 1 , tetapi bias anya dinyatakan dalam pers en. Perbedaan sudut fasa antara arus dan tegangan dinamakan faktor daya. Faktor daya untuk beban induktif adalah faktor daya yang tertinggal (lagging) karena beban menarik daya reaktif dari jala jala. Sedangkan beban kapasitif faktor daya nya mendahului (leading) dimana beban memberikan daya reaktif ke jala jala

\section{E. Perbaikan Faktor Daya}

Pada beban induktif, perbaikan faktor daya dilakukan dengan menyalurkan arus leading dari suatu sumber daya reaktif kapasitif sehingga dapat mengkompensasi arus lagging yang diserap beban tersebut. Perbaikan faktor daya beban kapasitif dilakukan dengan memasang sumber daya reaktif induktif. Seperti yang telah diketahui, pemasangan kapasitor pada beban induktif akan memperbaiki faktor daya beban. Hal ini disebabkan karena kapasitor akan menarik arus kapasitif dari jala-jala pada saat tegangan bertambah menuju nilai maksimum dan menyimpan energi yang diserap dari jala-jala dalam bentuk medan listrik elektrostatis.

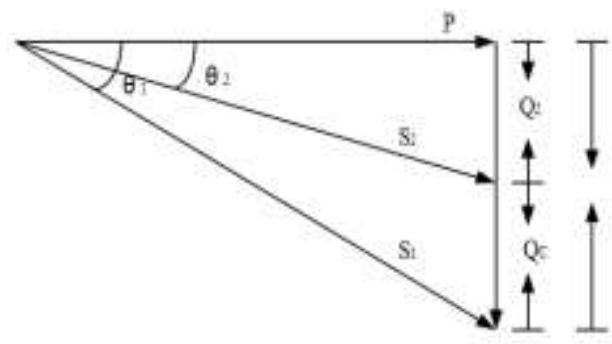

Gambar 3 Power Factor Correction

Pada periode waktu berikutnya saat nilai tegangan semakin menurun, energi yang diserap oleh kapasitor akan dilepaskan dan akan digunakan oleh beban induktif untuk membangkitkan medan magnetik. Oleh karena itu, apabila kapasitor dan beban induktif dipasang pada rangkaian yang sama maka akan terjadi pertukaran arus reaktif diantara keduanya. Jadi kebutuhan daya reaktif beban induktif dapat diperoleh dari kapasitor yang berfungsi sebagai pembangkit daya reaktif. Dengan demikian daya reaktif yang ditarik oleh beban induktif dari jala-jala dapat 
dikurangi. Pengurangan daya reaktif menyebabkan arus yang ditarik beban dari jalajala dapat berkurang.

Gambar 3 adalah gambar perbaikan faktor daya dengan kompensator daya reaktif (kapasitor). Kapasitas kapasitor yang dibutuhkan untuk memperbaiki faktor daya beban dapat dihitung sebagai berikut:

Daya reaktif pada p.f awal

$$
Q 1=P \times \tan \theta 1
$$

Daya reaktif pada p.f yang diperbaiki

$$
Q 2=P \times \tan \theta 2
$$

dimana $\mathrm{P}=$ konstan

Sehingga rating kapasitor yang diperlukan untuk memperbaiki faktor daya adalah :

$$
\text { Daya Reaktif } Q c=Q 1-Q 2
$$

Atau

$$
\Delta Q=P \times(\tan \theta \text { awal }-\tan \theta \operatorname{target})
$$

\section{F. Kapasitor Bank}

Dalam perbaikan faktor daya dan pengaturan tegangan jaringan, para engineer menggunakan kapasitor bank dengan sistem kompensasi daya reaktif yang ditawarkannya. Pada saluran transmisi, beban yang bersifat induktif akan menyerap daya reaktif, yang kemudian akan dapat menimbulkan jatuh tegangan di sisi penerima. Disinilah kapasitor bank berfungsi dalam mengkompensasi daya reaktif dan memastikan tegangan terjaga pada levelnya pada saat beban penuh. Pemasangan kapasitor bank adalah usaha yang dilakukan untuk memberikan supply daya reaktif. Sehingga penggunaan kapasitor bank akan mengurangi penyerapan daya reaktif sistem oleh beban. Hal ini dilakukan agar jatuh tegangan dan rugi-rugi jaringan yang terjadi dapat dikurangi.

Secara umum fungsi kapasitor pada sistem tenaga adalah :

a. Menyuplai daya reaktif sehingga memaksimalkan penggunaan daya kompleks (KVA)

b. Memperbaiki power faktor

c. Mengurangi jatuh tegangan

d. Menghindari kelebihan beban trafo

e. Memberi tambahan daya tersedia

f. Menghindari kenaikan arus dan suhu pada kabel

g. Menghemat daya / efisiensi

Selain dapat memperbaiki nilai tegangan, pengaturan tegangan dengan menggunakan kapasitor bank juga dapat meningkatkan nilai faktor daya. Sebab dengan memasang kapasitor bank, akan dapat mengurangi penyerapan daya reaktif oleh beban. Pengurangan penyerapan daya reaktif oleh beban pada sistem, akan dapat meningkatkan nilai faktor daya. Kapasitor bank memberikan manfaat yang besar untuk kinerja sistem distribusi. Dimana kapasitor bank dapat mengurangi losses, memperbesar kapasitas layanan dan mengurangi drop tegangan.

Rugi-rugi jaringan - dengan memberi kompensasi daya reaktif pada motor dan beban lainnya dengan power faktoryang rendah, kapasitor akan menurunkan arus jaringan. Penurunan arus ini akan mengurangi rugi-rugi I2R jaringan secara signifikan. Kapasitas - penurunan arus di jaringan ini lebih lanjut akan memperbesar kapasitas pelayanan dimana, jaringan yang sama akan dapat melayani beban yang lebih besar. Drop tegangan - kapasitor bank dapat mengurangi voltage drop dimana dengan kompensasi daya reaktif akan meningkatkan / menaikkan level tegangan jaringan.

\section{G. Kompensasi daya reaktif}

Berdasarkan lokasi penempatan kapasitor bank kompensasi daya reaktif terbagi menjadi tiga, yaitu :

- Kompensasi Sentral

Seluruh kebutuhan daya reaktif dipusatkan pada satu titik, yaitu pada saluran distribusi utama. Dengan demikian susunan rangkaian kompensasi ini paling ekonomis bila dibandingkan dengan kompensasi jenis lain. Kelemahannya adalah apabila beban yang terpasang sangat kecil maka akan terjadi tegangan lebih pada sistem. Selain itu rugi daya pada saluran tidak berkurang karena kapasitor bank hanya dapat mengurangi rugi daya pada transformator di atasnya.

\section{- Kompensasi Sektoral}

Kapasitor bank diletakkan pada kelompok - kelompok beban yang letaknya berdekatan. Keuntungannya adalah rugi daya pada saluran dari sumber sampai lokasi kapasitor dapat berkurang Akan tetapi rugi daya pada saluran dari lokasi kapasitor bank sampai ke beban tidak berkurang, Kelemahan lainnya adalah masih adanya kemungkinan terjadi kelebihan kompensasi pada sektor apabila terjadi perubahan beban yang sangat besar. Hal ini dapat diatasi dengan menggunakan kompensasi bertahap.

- Kompensasi Lokal

Kapasitor bank diletakkan pada tiap-tiap beban sehingga merupakan kompensasi yang paling mahal. Akan tetapidengan menggunakan kompensasi lokal maka rugi daya dari sumber ke beban sangat besar. Kompensasi jenis ini biasanya digunakan pada beban tunggal yang besar.

\section{OPTIMASI GENETIC ALGORITHM (GA)}

\section{A. Genetic Algorithm (GA)}

Metoda Genetic Algorithm (GA) adalah algoritma yang memanfaatkan proses seleksi alamiah yang dikenal dengan proses evolusi. Dalam proses evolusi, individu secara terus mengalami perubahan gen untuk menyesuaikan dengan lingkungan hidupnya. Hanya Individu-individu yang kuat yang bertahan hidup.

Metoda Genetic Algorithm (GA) dapat membantu memecahkan permasalahan dalam sistem tenaga. Pengkodean di dalam GA secara umum dalam bentuk binner yang menjadi sebuah string (rangkaian) yang menyusun gen-gen pembentuk kromosom. Kemudaian akan mencari solusi dan fitness terbaik sesuai dengan fungsi objektif yang digunakan. Parameter yang digunakan di dalam GA adalah Generation (jumlah maksimal generasi), Popsize (jumlah populasi), probability crossover dan mutation. Pembangkitkan secara acak dan kemudian akan dipilih melalui operasi Genetika (selection, crossover, mutation). Hasil dari operasi Genetika tersebut akan dievaluasi sesuai dengan fungsi objektif yang digunakan sehingga didapatkan kromosom yang akan diikutkan proses perulangan. Proses evolusi GA akan berhenti ketika sudah mencapai Generatian yang ditentukan.

\section{B. Bagian bagian Genetic Algorithm (GA)}


Terdapat bagian bagian penting yang harus diketahui pada Genetic Algorithm. Pada pelaksanaannya, algoritma genetika menggunakan istilah dari disiplin ilmu biologi. Hal tersebut disebabkan karena algoritma genetika menerapkan teori evolusi dan seleksi yang terjadi di alam. Beberapa bagian bagian yang dipergunakan dalam algoritma genetika dalam mendefinisikan individu untuk menyelesaikan permasalahan diantaranya sebagai berikut :

\section{- Gen}

Gen merupakan elemen terkecil dalam sistem makhluk hidup yang membawa sebuah nilai di dalam individu, nilai yang dimaksud biasa disebut allele. Biasanya gen pada Genetic Algorithm (GA) berbentuk binner, float ataupun string. Sedangkan dalam tugas akhir ini menggunakan metode Genetic Algorithm (GA) jenis binner, sehingga parameter gen disini berupa angka binner nol dan satu. Dan setiap gen memiliki dan mengandung nilai tersendiri.

\section{- Kromosom}

Kromosom adalah kumpulan dari gen-gen yang membentuk satu kesatuan individu tertentu. Sedankan untuk banyaknya gen di dalam kromosom tergantung dari optimasi yang dilakukan dan jumlah kapasitor yang akan dioptimasi.

\section{- Individu}

Individu merupakan kesatuan dari kromosom yang memiliki satu fitness. Individu merupakan representasi dari sebuah kromosom. Pada tugas akhir ini individu membawa nilai fitness berupa perbaikan power faktor pada sistem kelistrikan PT. Semen Indonesia Aceh dan penempatan kapasitor dan nilai kapasitor yang dinjekkan.

\section{- Populasi}

Populasi adalah sekumpulan individu yang memiliki fitness masing-masing. Pada populasi inilah akan dipilih induk untuk dilakukan regenerasi atau perkawinan, sehingga setiap generasi akan terjadi pembaharuan (update) pada populasi. Dalam tugas akhir ini, dilakukan beberapa kali percobaan (trial) untuk mendapatkan berapa besar ukuran populasi (popsize) yang dianggap sudah dapat menemukan solusi di setiap optimasi. Pada tugas akhir ini besarnya populasi adalah 20.

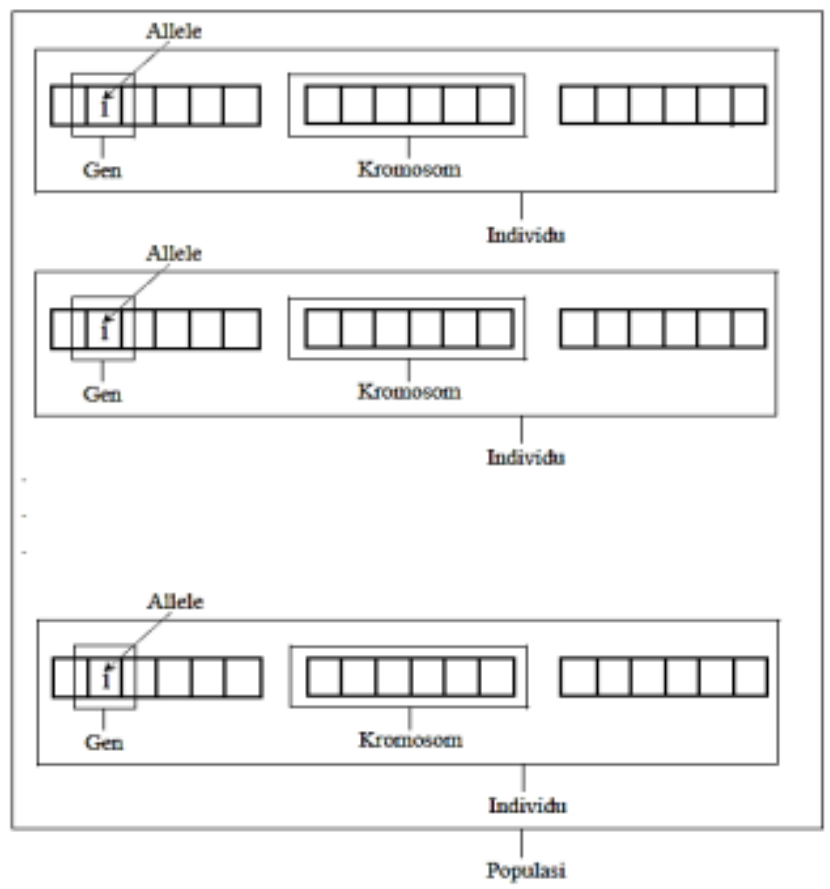

Gambar 4 Bagian bagian pada Genetic Algorithm

\section{- Generasi}

Generasi adalah jumlah keturunan dari proses seleksi alami. Proses ini dimulai dengan satu populasi hingga membentuk populasi baru dengan gen-gen yang berbeda-beda.

\section{- Fungsi Obyektif}

Fungsi fitness adalah salah satu bagian yang paling penting dalam Genetic Algorithm. Merupakan sebuah persamaan fungsi yang memiliki peran untuk menghitung nilai sebuah kromosom. Persamaan ini adalah persamaan yang dibentuk dari sistemada dengan memperhatikan apa yang direpresentasikan didalam kromosom untuk menghasilkan berapa besarnya nilai kromosom tersebut.

Nilai fitness dari kromosom kromosom ini bermanfaat untuk proses selanjutnya, yaitu sebagai perbandingan untuk menghasilkan induk baru calon kawin silang. Dengan kata lain nilai fitness adalah nilai dari fungsi objektif permasalahan dari setiap individu. Nilai ini akan digunakan sebagai pembanding dalam pemilihan individu terbaik sebagai solusi paling optimal. Fitness merupakan hasil minimisasi dari fungsi objektif, dimana pada tugas akhir ini hanya ada satu fungsiobjektif, yaitu perbaikan power factor.

\section{Variabel Genetic Algorithm}

Terdapat beberapa parameter variable pada metode Genetic Algorithm (GA) dan beberapa parameter digunakan dalam melakukan optimasi [3]. Parameter ini memiliki nilai yang akan mempengaruhi proses optimasi yang berhubungan dengan kecepatan pencarian solusi terbaik. Berikut Parameter yang digunakan dalam metoda Genetic Algorithm (GA) :

\section{- Jumlah Generasi (MAXGEN)}

Merupakan jumlah maksimum generasi. Yang berarti jumlah maksimum perulangan (iterasi) yang dilakukan untuk mencapai nilai optimasi. Jumlah generasi ini mempengaruhi kestabilan output dan lama iterasi (waktu proses Genetic Algorithm). Jumlah generasi yang besar dapat mengarahkan kearah solusi yang optimal, namun akan membutuhkan waktu yang lama. 
Sedangkan jika jumlah generasinya terlalu sedikit maka solusi akan terjebak pada local optimum.

Dengan kata lain Max generasi merupakan jumlah generasi dari hasil perkawinan silang (crossover) atau keturunan yang ingin digunakan dalam satu kali proses evolusi. Pada tugas akhir ini dilakukan beberapa kali percobaan dimana pada generasi berapa tidak ada lagi perubahan atau tidak ada lagi invidu yang lebih baik. Kemudian baru menentukan berapa max generasi. Untuk optimasi digunakan max generasi $100 .$.

\section{- Ukuran Populasi (POPSIZE)}

Ukuran populasi merupakan parameter GA yang berisi nilai jumlah individu di dalam populasi pada setiap generasi. Besarnya popsize akan mempengaruhi pencarian solusi yang optimal. Hal ini dikarenakan populasi yang besar memiliki keberagaman jenis individunya. Ukuran populasi ini mempengaruhi kinerja dan efektifitas Genetic Algorithm.

Jika ukuran populasi kecil maka populasi tidak menyediakan cukup materi untuk mencakup ruang permasalahan, sehingga pada umumnya kinerja GA akan menjadi buruk. Dalam hal ini dibutuhkan ruang yang lebih besar untuk merepresentasikan keseluruhan ruang permasalahan. Selain itu penggunaan populasi yang besar dapat dapat mencegah terjadinya konvergensi pada wilayah local namun prosesnya cukup lama. Dalam tugas akhir ini, dilakukan beberapa kali percobaan (trial) untuk mendapatkan berapa besar ukuran populasi (popsize) yang dianggap sudah dapat menemukan solusi di setiap optimasi. Pada tugas akhir ini besarnya populasi adalah 20

\section{- Panjang Kromosom (NVAR)}

Merupakan panjang dari deret deret gen yang membentuk satu kromosom. Jadi NVAR adalah jumlah gen gen dalam satu kromosom itu sendiri. Gen gen ini merupakan parameter parameter dari suatu obyek yang akan di optimasikan melalui segala proses dalam GA tersebut. Semakin panjan nilai dari NVAR akan memperlama proses GA, namun hasil yang diperoleh akan menjadi lebih kompleks.

\section{- Probabilitas crossover (PC)}

Probabilitas crossover (PC) merupakan nilai kemungkinan dari terjadinya crossover pada saat perkawinan. Referensi mengatakan nilai PC berkisar antara 0 sampai 1. Jika nilai PC semakin besar maka kemungkinan terjadinya crossover juga semakin besar dan sebaliknya. Kemungkinan $100 \%$ terjadinya crossover dapat dilakukan dengan memberikan nilai 1 pada parameter PC dan sebaliknya.

Kemungkinan terjadinya crossover adalah diantara $0-1$ dan dipilih 0,8. Pada tugas akhir ini menggunakan PC 0,95. Pemilihan ini bertujuan untuk memberikan kemungkinan terbesar agar terjadinya crossover, sehingga setiap generasi mengalami perubahan dan ini akan mempercepat menemukan solusi dan proses konvergensi.

\section{- Probabilitas Mutasi (PM)}

Probabilitas Mutasi (PM) adalah nilai kemungkinan dari terjadinya mutasi pada gen-gen pembentuk kromosom [3]. Mutasi terjadi setelah crossover pada perkawinan. Referensi mengatakan nilai PM memiliki nilai yang kecil seperti 0,05, 0,1 atau selainnya. Jika nilai PM semakin kecil maka kemungkinan terjadinya mutasi juga semakin kecil dan sebaliknya. Nilai PM ini pada umumnya berkisar antara 0 hingga 0,3 . Sesuai dengan referensi kemungkinan terjadinya mutasi bernilai kecil dengan nilai 0,1 . Pada tugas akhir ini menggunakan PC 0,05 . Pemilihan ini bertujuan untuk memberikan kemungkinan terkecil agar terjadinya mutation.

\section{Pengkodean Kapasitor}

Langkah pertama kali yang dilakukan dalam penggunaan Genetic Algorithm adalah melakukan pengkodean atau representasi terhadap permasalahan yang akan dilakukan. Kode kode tersebut yang lazim dipakai dalam Genetic Algorithm seperti kode biner, bilangan real, huruf dan sebagainya. Pada tugas akhir ini optimasi penempatan dan nilai kapasitor adalah untuk memperbaiki nilai power faktor dan menggunakan pengkodean bilangan biner.

Pengkodean binner untuk kapasitor, pertama untuk penempatan dan kedua untuk ukuran atau kapasitas. Untuk penempatan pengkodean binner tegantung dari jumlah bus sistem, karena menggunakan plan PT Semen Indonesia Aceh terdapat 20 bus, yang diklasifikasikan bus menurut medium voltage. maka jumlah pengkodean busnya adalah dibulatkan menjadi 32 bus. Kemudian untuk pengkodean ukuran tergantung dari berapa banyak variasi ukuran yang diinginkan. Gambar 4 berikut adalah gambar pengkodean biner kapasitor menurut penempatan bus dan variasi nilai.

\section{- Pengkodean binner}

Pengkodean binner untuk kapasitor, pertama untuk penempatan dan kedua untuk ukuran atau kapasitas. Untuk penempatan pengkodean binner tegantung dari jumlah bus sistem. Kemudian untuk pengkodean ukuran tergantung dari berapa banyak variasi ukuran yang diinginkan. Gambar 5 adalah gambar pengkodean binner kapasitor .

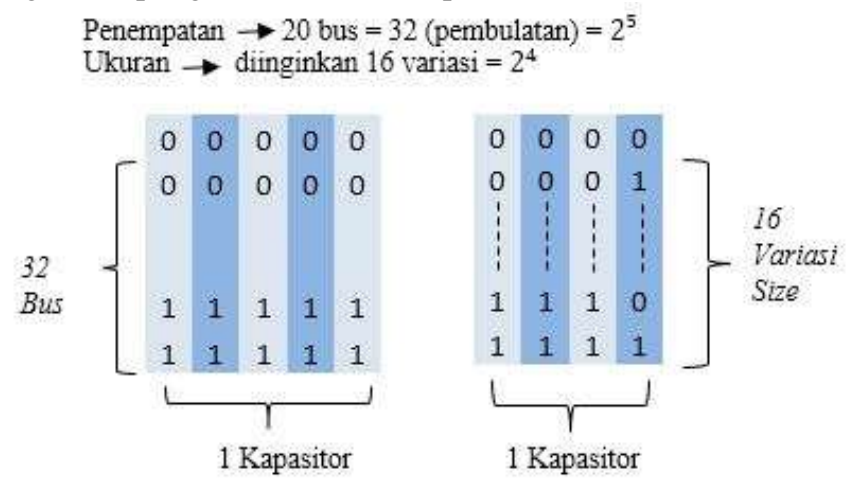

Gambar 5 Pengkodean biner kapasitor

\section{- Panjang binner (NSBIT)}

Pengkodean Untuk Nsbit satu kapasitor membutuhkan 9 bit. Jika pemasangan kapasitor lebih dari satu, maka jumlah bit yang dibutuhkan disesuaikan dengan jumlah kapasitornya (9bit dikali jumlah kapasitor) .

Gambar 6 merupakan contoh decoding dari penempatan dan ukuran kapasitor, dimana penempatan kapasitor pada bus 20 dan ukurannya 1 MVar.

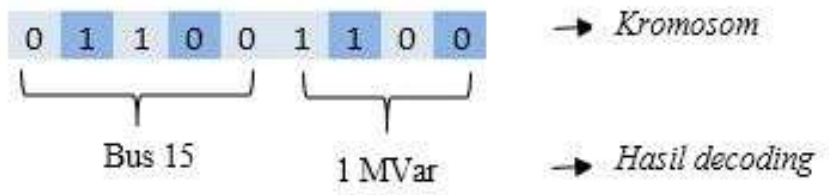

Gambar 6 Decoding kapasitor

\section{E. Proses Optimasi Menggunakan Genetic Algorithm (GA)}


Secara garis besar, proses optimasi menggunakan Genetic Algorithm (GA) dilakukan dengan langkah sebagai berikut :

1. Pembacaan data dan parameter

Proses pertama ini adalah adalah pembacaan data sistem kelistrikan PT. Semen Indonesia Aceh berupa line data, bus data. Kemudian parameter GA dan parameter lainnya.

\section{Membangkitkan Populasi}

Ukuran populasi yang dibangkitkan sesuai dengan keinginan, misalnya 10, 20, 50 dan seterusnya. Populasi dibangkitan secara acak yang mana bernilai angka binner nol dan satu. Kemudian Nsbit dari tiap kromosom tergantung dari scenario yang dilakukan.

\section{Decoding Kromosom}

Semua kromosom akan diuraikan (parsing) berdasarkan scenario yang dilakukan. Kemudian semua kromosom pada populasi akan diartikan (decoding) dan menghasilkan solusi awal.

4. Evolusi

Pada proses ini dimulailah proses penseleksian induk (random selection), kemudain crossover, mutasi sehingga menghasilkan anak baru (offspring). Proses evolusi ini akan terus terjadi (perulangan) hingga mencapai generasi yang telah ditentukan.

\section{Evaluasi}

Anak baru (offspring) yang mengalami perubahan gen-gen dari induknya akan diartikan (decoding) sehingga menghasilkan solusi. Solusi ini akan di terapkan pada sistem kelistrikan PT. Semen Indonesia Aceh (update sistem) kemudian dilakukan load flow. Dari hasil load flow didapatkan nilai deviasi tegangannya dan disimpan di dalam fitness $i$.

6. Fitness terbaik

Setelah melakukan evaluasi maka dilakukan pemilihan individu yang memiliki fitness terbaik berdasarkan batasan (constraint) yang ada. Sehingga individu yang akan dipilih nantinya merupakan individu yang sudah memenuhi kriteria atau constraint dan memiliki fitness terkecil. Di dalam individu ini sudah terdapat solusi dari scenario optimasi yang dilakukan.

\section{SIMULASI DAN ANALISA}

Pada tugas akhir ini simulasi optimasi untuk memperbaiki nilai power factor yang diujikan pada sistem kelistrikan distribusi radial PT Semen Indonesia Aceh, dengan beberapa scenario optimasi yang didasarkan pada percobaan pertambahan jumlah kapasitor yang dipasang. Metode yang digunakan untuk pencarian solusidan fitness terbaik pada setiap scenario adalah metode Genetic Algorithm (GA). Yang nantinya akan dicari hasil optimasi yang terbaik. Berikut adalah scenario yang dilakukan :

a. Load flow awal

b. Scenario 1 penambahan 5 kapasitor

c. Scenario 2 penambahan 6 kapasitor

d. Scenario 3 penambahan 7 kapasitor

e. Scenario 4 penambahan 8 kapasitor

f. Scenario 5 penambahan 9 kapasitor

g. Scenario 6 penambahan 10 kapasitor

h. Scenario 7 penambahan 11 kapasitor

Dari setiap scenario (1-7) yang dilakukan, akan dicari scenario terbaik yang menghasilkan solusi dan fitness yang memiliki nilai power factor yang tertinggi. Solusi dan fitness tersebut akan dianalisa. Sehingga akan menghasilkan kesimpulan dari optimasi yang dilakukan. Pada scenario 1 hanya dilakukan loadflow saja sebagai data awal.

\section{A. Load flow awal( Base)}

Dari gambar 7 sebelum optimasi diketahui bahwa masih banyak power factor bus yang berada di bawah range atau batas an yang diijinkan. Dan bus yang paling rendah nilai power factornya adalah bus 13 dengan nilai power factor 0,59 dengan rugi daya sistem sebesar $1118,9 \mathrm{KW}$.

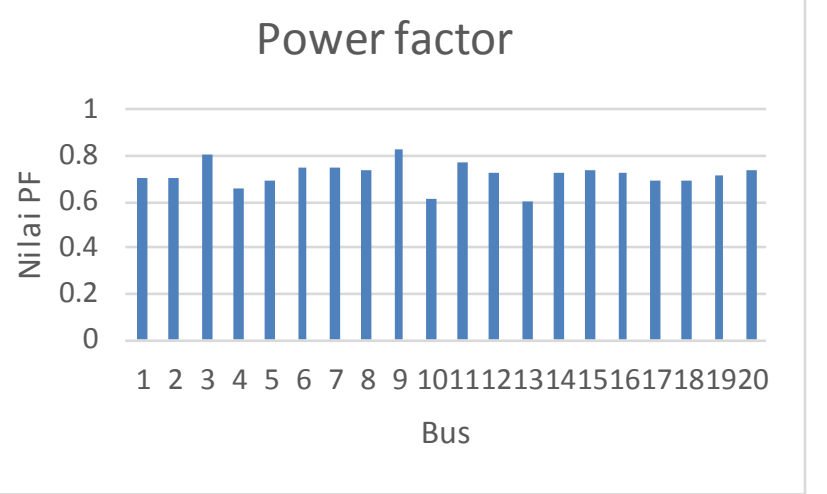

Gambar 7 Power Factor awal sebelum pemasangan kapasitor

\section{B. Scenario 1,2}

Pada scenario 1 dan 2 Pada scenario ini dilakukan optimasi dengan cara menambahkaan 5 dan 6 kapasitor pada sistem kelistrikan distribusi radial PT Semen Indonesia Aceh. Dan hasil yang didapat power factor sistem masih berkisar di nilai 0,7 .

\section{Scenario 3,4,5,6}

Pada scenario 3,4,5,6 ini dilakukan optimasi dengan cara menambahkaan 7,8,9,10 kapasitor pada sistem kelistrikan distribusi radial PT Semen Indonesia Aceh. Dan hasil yang didapat power factor sistem masih berkisar di nilai 0,8 .

\section{Scenario 7}

Pada scenario 7 ini dilakukan optimasi dengan cara menambahkaan 11 kapasitor pada sistem kelistrikan distribusi radial PT Semen Indonesia Aceh. Dan hasilyang didapat adalah sebagai berikut :

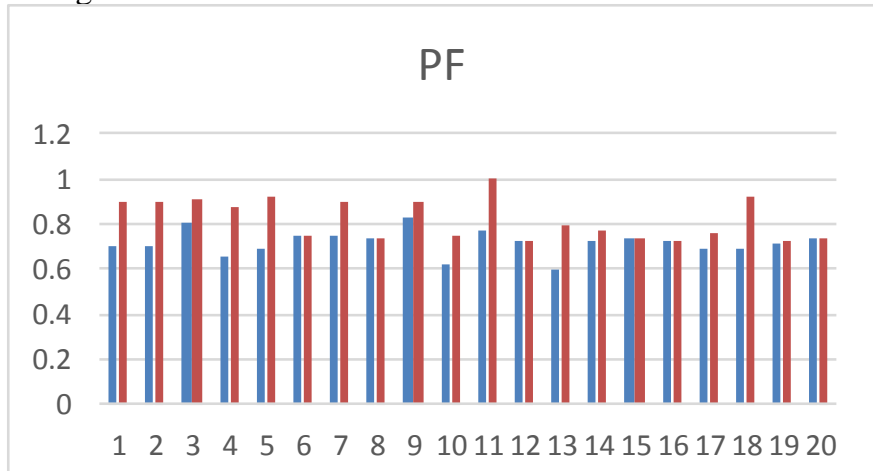

Gambar 8 Power Factor scenario 7 setelah pemasangan kapasitor

Dari gambar 8 setelah optimasi scenario 7, diketahui bahwa power factor bus bernilai 0,9 dan ini sudah menjadi bagus. dengan rugi daya sistem sebes ar 714,3 KW. 


\section{E. Perbandingan Power Factor hasil optimasi}

Setelah dilakukan percobaan optimasi pada sistem kelistrikan PT. Semen Indonesia Aceh menggunakan metode Genetic Algorithm diperoleh hasil sebagaiberikut. Pada gambar 9 ditampilkan perbandingan power factor dari sebelum pemasangan kapasitor atau load flow awal dengan hasil setelah pemasangan kapasitor dengan scenario 1,2,3,4,5,6,7. Pada sistem kelistrikan awal power faktor sistem sebesar 0,7032. Setelah dilakukan optimasi scenario 1 dan scenario 2 dengan penambahan 5 dan 6 kapasitor dan hasilnya masih di titik power factor 0,7. Baru Setelah dilakukan optimasi scenario 3,4,5,6 dengan penambahan kapasitor 7,8,9,10 maka hasil power factor perlahan naik mencapai titik 0,8. Dan setelah dilakukan optimasi yang terakhir yaitu scenario 7 , maka didapatkan hasil power factor yang mencapai 0,9 . Dan inilah hasil optimasi yang akan dipakai. Berikut gambarannya :

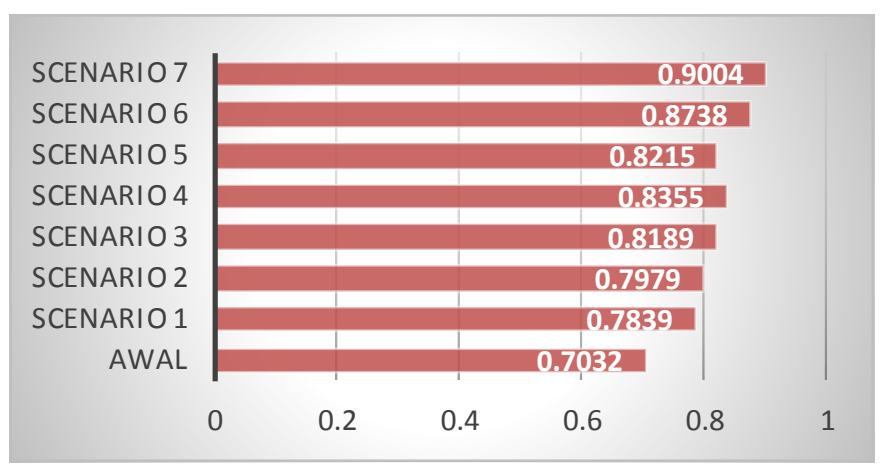

Gambar 9 Perbandingan hasil optimasi tiap scenario

\section{KESIMPULAN}

Setelah melakukan simulasi dan analisis didapatkan hasil simulasi optimasi penyaluran daya reaktif dengan menggunakan metode Genetic Algorithm dalam menentukan lokasi dan kapasitas kapasitor bank yang akan dipasang pada bus bus sistem kelistrikan PT Semen Indonesia Aceh maka dapat diambil beberapa kesimpulan sebagai berikut :

1. Penentuan lokasi dan kapasitas kapasitor bank menggunakan metode Genetic Algorithm (GA) dapat memperbaiki faktor daya dimana sistem yang ada sebelum optimasi sebesar 70,4 dan setelah optimasi menjadi sebesar 90,04 .

2. Hasil paling optimal didapat pada scenario 7 dengan penambahan 11 kapasitor yang ditempatkan pada tiap tiap bus.

3. Dengan penentuan lokasi pemasangan kapasitor bank yang optimal, maka dapat mengurangi rugi rugi daya sebesar 1118,9 Kw menjadi 714,3 Kw.

4. Optimasi Penentuan lokasi dan kapasitas kapasitor bank juga dapat memperbaiki profil tegangan sistem.

\section{LAMPIRAN}

Table Load Data Bus

\begin{tabular}{ccc}
\hline \hline & Data Bus \\
Bus & $\mathrm{P}(\mathrm{MW})$ & $\mathrm{Q}$ (MVAR) \\
\hline 2 & 0.000 & 0.000 \\
3 & 0.000 & 0.000 \\
4 & 0.281 & 0.116 \\
\hline \hline
\end{tabular}

\begin{tabular}{|c|c|c|c|}
\hline$\overline{5}$ & \multicolumn{2}{|c|}{0.000} & $\overline{0.000}$ \\
\hline 6 & \multicolumn{2}{|c|}{1.495} & 1.191 \\
\hline 7 & \multicolumn{2}{|c|}{0.961} & 0.777 \\
\hline 8 & \multicolumn{2}{|c|}{0.610} & 0.515 \\
\hline 9 & \multicolumn{2}{|c|}{7.164} & 4.387 \\
\hline 10 & \multicolumn{2}{|c|}{8.248} & 8.862 \\
\hline 11 & \multicolumn{2}{|c|}{2.293} & 1.559 \\
\hline 12 & \multicolumn{2}{|c|}{0.641} & 0.515 \\
\hline 13 & \multicolumn{2}{|c|}{3.096} & 3.489 \\
\hline 14 & \multicolumn{2}{|c|}{1.570} & 1.279 \\
\hline 15 & \multicolumn{2}{|c|}{0.526} & 0.411 \\
\hline 16 & \multicolumn{2}{|c|}{0.858} & 0.694 \\
\hline 17 & \multicolumn{2}{|c|}{5.873} & 5.337 \\
\hline 18 & \multicolumn{2}{|c|}{5.809} & 5.284 \\
\hline 19 & \multicolumn{2}{|c|}{1.087} & 0.925 \\
\hline 20 & \multicolumn{2}{|c|}{0.868} & 0.698 \\
\hline \multicolumn{4}{|c|}{ Table Line Data Bus } \\
\hline \multicolumn{4}{|c|}{ Data Impedasi Saluran } \\
\hline Bus & Bus & $\mathrm{r}$ & $\mathrm{x}$ \\
\hline 1 & 2 & 0.000000 & 0.000000 \\
\hline 2 & 3 & 0.021335 & 0.185315 \\
\hline 2 & 4 & 0.021335 & 0.185315 \\
\hline 2 & 5 & 0.021335 & 0.185315 \\
\hline 3 & 6 & 0.052081 & 0.078772 \\
\hline 3 & 7 & 0.127596 & 0.076818 \\
\hline 3 & 8 & 0.163382 & 0.061923 \\
\hline 3 & 9 & 0.077093 & 0.046413 \\
\hline 4 & 10 & 0.025173 & 0.039726 \\
\hline 4 & 11 & 0.031467 & 0.041300 \\
\hline 11 & 12 & 0.199732 & 0.044551 \\
\hline 4 & 13 & 0.018596 & 0.034900 \\
\hline 4 & 14 & 0.021200 & 0.005200 \\
\hline 4 & 15 & 0.129425 & 0.049053 \\
\hline 4 & 16 & 0.059225 & 0.022446 \\
\hline 5 & 17 & 0.013740 & 0.082146 \\
\hline 5 & 18 & 0.013740 & 0.082146 \\
\hline 18 & 19 & 0.224000 & 0.049965 \\
\hline 5 & 20 & 0.05522 & 0.062790 \\
\hline
\end{tabular}

\section{DAFTAR PUSTAKA}

[1] Ahmad Galal Sayed and Hosam K.M Youssef, "Optimal Sizing of Fixed Capacitor Banks Placed on a Distorted Interconnected Distribution Networks by Genetic Algorithms”, IEEE journal, 2008.

[2] Mesut E. Baran and Allan Felix F. Wu, "Optimal Sizing of Capacitors Placed on a Radial Distribution System", IEEE journal, 1989.

[3] Randy L. Haupt, Sue Ellen Haupt "Pratical Genetic Algorithm", John Wiley \& Sons, Inc. All rights reserved, Canada,2004 